\title{
SID Food Security Network and Partner Organizations
}

\section{Bangladesh}

BRAC aims to bring about a positive change in the quality of life of the poor people of Bangladesh. BRAC is committed to making its programmes socially, financially, and environmentally sustainable, using innovative methods and appropriate technologies. BRAC firmly believes and is actively involved in promoting human rights, human dignity, and gender equity.

SID Sylhet Chapter is concerned with issues of poverty, food security and sustainable human development. The unit is linked to organizations running micro-credit programmes for enhancement of household food security and empowerment of local women.

\section{Benin}

Songhai Centre's mission is to provide an atmosphere where young Africans can develop the will and desire for a better quality of life. From a sustainable livelihoods approach, the organization focuses on production, training, research and development. Songhai assists young farmers in the improvement of their enterprises and trains school drop outs in crop production, animal husbandry, aquaculture, food processing and marketing. It promotes knowledge on the techniques and patterns of rural mobilization in order to reinforce the organization of grassroots communities.

\section{Bolivia}

SID Cochabamba Chapter and Centro de Estudios de la Realidad Económica y Social (CERES) CERES closely works with SID Cochabamba Chapter in fostering human development and sustainable livelihoods. The Centre accomplishes research on a number of issues related to the food security domain, in particular on urban agriculture and household food security. It often works in cooperation with a number of national and international partners concerned with food security and sustainable development.

\section{Brazil}

Associação para Projetos de Combate á Fome (Ágora) Ágora is a civil society organization based in Brasilia with the established mission of promoting Food and Nutritional Security for all, through the strengthening of local integrated development. Ágora concentrates its work on food and nutritional security and is oriented towards local integrated development projects (food for work, microcredit, sustainable livelihoods, community capacity building). It also plays an important role as focal point for national, regional and global networks on food and nutritional security, working in close partnership with NGOs and popular movements.

\section{Burkina Faso}

Association Vive le Paysan works to improve the livelihoods of rural dwellers in Burkina Faso by means of awareness creation and empowerment initiatives. It seeks to introduce and promote the use of innovative techniques for agricultural production and natural resources management; improve human and animal health; counter illiteracy and enhance leadership/management skills at the community level; and strengthen women's organizations. Its programmes include a focus on soil regeneration, water management, community and individual tree planting; seed selection; establishment of village chemists and centres for formal education of children/informal education of adults; gender issues; animation and organization of discussion forums on cereal banks and micro-credit schemes.

\section{Cameroon}

SID Douala Chapter and Association for Development Communication and Environment 
(ADCOME) ADCOME closely works with SID Douala Chapter for the mobilization and empowerment of rural communities. The association focuses on the opportunities opened by the use of new information and communication technologies at the rural/grassroots level. Activities include research, seminars and training to the benefit of local communities and especially rural women.

Changing Mentalities and Empowering Group through Small Business Initiative (CHAMEG SBI) works for equity, fair representation and assistance to disadvantaged groups in society and especially women. It counts 2000 members and serves about 200 groups. The organization's mission is to alleviate poverty through self-help and its activities include training, credit, business advisory services, research and communication (use of Internet and telephone facilities).

\section{Côte d'Ivoire}

Tha-meri is a national NGO composed of institutional and individual members aiming to foster a culture of peace and environmental conservation. To this end, three main tracks have been identified for the activities of the organization, namely food security, education and health. It particularly focuses on women and rural youth groups by means of social mobilization processes and publications.

\section{El Salvador}

Fundación Salvadoreña de Desarrollo y Vivienda Mínima (FUNDASAL) work focuses on human development and especially targets the social and politically marginalized sectors of the population in both rural and urban areas. In addressing eradication of poverty and exclusion, FUNDASAL tries to modify some of the structural causes at the roots of such phenomena. The organization works to involve the poorest in processes of change, create room for participation, self-procurement, social organization and empowerment towards sustainable livelihoods and development of these groups.

\section{Ghana}

African Development Programme (ADP) works to promote human development through integrated programmes targeted at rural and peri-urban communities. Its activities include a focus on basic education, primary health care, governance, humanitarian/disaster relief and micro-enterprise development.

\section{SID Legon Chapter and African Association for Health, Environ- ment and Development (AAHEAD) is an organization particularly con- cerned with issues of food security, reproductive health, environment conservation and sustainable development. Its niche is the cataly- sation of social mobilization and awareness processes at the com- munity level, though organization of workshops and community ani- mation events.}

\section{Haiti}

Plateforme de Plaidoyer pour un Développement Alternatif (PAPDA) is an advocacy organization looking for alternative development patterns in the search for food security and advocacy. From a sustainable livelihoods perspective, the organization tries to establish micro-macro linkages and ongoing dialogue between civil society and the state. Its activities include organization of social mobilization processes at the small farmers level, distribution of pedagogical kits on food insecurity, valorization of traditional eating habits and recipes, literary competitions in school on the theme of food security, organization of local produce fairs, etc.

\section{India}

Lokayan is a Delhi-based organization dedicated to the promotion of dialogue and exchange among nonparty political organizations and movements and other concerned citizens. Lokayan focuses on issues of sustainable livelihoods and food security, indigenous rights, ecological movements, social justice and reconceptualization of democracy in the contemporary world. The organization combines extensive local, activist involvement with global experiences and perspectives.

Centre for Women's Development Studies (CWDS) undertakes research on a wide selection of women's issues. Particularly important is the centre's experience in supporting women's groups reclaiming waste land and consequent creation of income generation activities, revaluation of traditional activities and practices, soil regeneration activities and training. Vocational training is complemented by discussion groups dealing with issues such as possible challenges to the dowry practice, legal implications of social forestry etc. Grassroots projects confront women with a rather complex structure of democratic participation, enhancing their public exposure and leadership skills.

Institute for Development of Backward Regions (IDBR) works with the deprived and marginalized sections of society towards attainment of people-centred development. The IDBR's mission is to improve the quality of life of women and families 
through participatory initiatives, research activities and training programmes. The institute promotes the participation of grassroots level organization in decision-making. It cooperates with international and national agencies to implement its work in the rural and poverty stricken pockets, and supports national efforts for poverty alleviation through women's empowerment and social mobilization.

\section{Kenya}

New Opportunities Network (NEON) is a NGO network working on food security, agricultural development, natural resources management, rural development and poverty alleviation. It focuses on the search for food security as a social process and interplay among historical processes, state interventions and household practices. It concentrates its research, animation and advocacy activities in rural settings, paying particular attention to the cultural transformations that have affected rural livelihoods over time.

\section{Mali}

Centre National d'Appui et de Formation pour le Développement des Ressources Humaines (CENAFOD) activities focus on local development and decentralization; civil society participation in decisionmaking and democratization; enhancement of human and social capital; capacity building and institutional mobilization; gender issues; research and project implementation. It targets community leaders and grassroots organizations, NGOs, the private sector, public servants and partners in development cooperation for enhanced understanding of community concerns and animation.

SID Bamako Chapter focuses on production style from cotton to food crops; fostering creation of social amenities in rural areas so as to make them more attractive; and lobbying for establishment of credit/banking facilities directly targeting small farmers.

\section{Mexico}

Promoción del Desarrollo Popular (PDP) works to promote a sustainable livelihoods approach to development and food security. Its activities focus on the strengthening of social mobilization processes and the encouragement of pluralistic dialogue among different actors of civil society, such as grassroots groups, enterprises, NGOs, governmental agencies and international organizations. PDP also strives to strengthen sustainable production, consumption and marketing practices that can truly benefit local communities.

\section{Mozambique}

União Nacional de Camponeses (UNAC) advocates for the development of agro-industrial activities, commercialization of agricultural produce and products from cattle breeding. It contributes to the development efforts of the cooperatives movement and farmers' organizations by supporting their empowerment through formal and non-formal education. In particular it conducts training courses on organization and management for farmer leaders as well as leadership, cooperation and environment awareness training and courses on agro-industrial production, commercialization and cattle breeding methods.

\section{Nepal}

Women's Rehabilitation Centre (WOREC) pursues enhancement of social justice by means of partici- patory approaches to community animation, promotion of bio-intensive farming and human development. Among its present projects are the creation of bio-intensive demonstration farms; promotion of health care and education in food security, food safety, nutrition, hygiene and reproductive health; creation of women's income generating groups to counter poverty and women's trafficking; community animation and revaluation of local culture as a means towards attainment of selfesteem; support to a Women's Council created by rural women to monitor and discuss legal, economic and cultural concerns affecting their livelihoods.

Rural Reconstruction Nepal (RRN) works to improve the lives of the poorest rural people, particularly rural women, small farmers, and the most disadvantaged and socially oppressed strata of Nepalese society. Its main goal is to provide them with opportunities for their own socioeconomic empowerment. RRN aims to empower grassroots organizations and people so that they can attain self-reliance and confidence for long term sustainable development. RRN has a fourfold integrated approach to development encompassing a focus on livelihoods, education, health and self-government.

Environment, Culture, Agriculture, Research and Development Society - Nepal (ECARDS - Nepal) works to empower the marginalized, subordinated, oppressed and exploited people by facilitating their organization and improving their socio-economic conditions through better management of resources. Its objectives include the establishment of self-reliant local level organizations tackling community problems from a local perspective; promotion of sustainable agriculture and environment-friendly natural resource 
management; awareness creation and poverty alleviation.

\section{Nicaragua}

Instituto de Promoción Humana (INPHRU) is a national NGO aiming to promote social change and economic transformation in the country. It pursues establishment of links among grassroots organizations, professional associations and other components of civil society for enhanced awareness and community empowerment. Its activities include programmes on food security, bio-intensive farming, children's rights, violence against women, housing and health.

\section{Niger}

Réseau MARP (Méthode Active de Recherche et de Planification Participative) is a network of organizations concerned with sustainable livelihoods. It concentrates on participatory action research and the identification of useful tools for capacity building of rural communities. The network has a major focus on food security, which aims to enhance the value of local strategies and community-led initiatives in this direction.

\section{Nigeria}

SID Zaria Chapter has been actively involved in food security activities with participation in the SID initiatives for food security and sustainable livelihoods and organization of a national workshop on Food Security, Social Mobilization and Community Empowerment.

\section{Pakistan}

SUNGI Development Foundation is an advocacy oriented NGO working to promote an integrated multi-sectoral approach to rural development.
Its activities include community based institutional development, gender focused initiatives, natural resources management, small sustainable village infrastructure projects, health and sanitation interventions, small rural enterprise development, capacity building, research action and policy advocacy for sustainable livelihoods.

\section{Sustainable Development Policy} Institute (SDPI) is an independent public interest think tank and research institute. It undertakes policy-oriented research and advocacy with a view to catalysing transition to sustainable human development, enhancement of peace, social justice, food security and wellbeing within and across generations. It provides advice to public, private and voluntary organizations on issues of public interest and socio-environmental relevance.

\section{Sustainable Agriculture Action} Group (SAAG) is a national level network of NGOs and CBOs, striving to promote sustainable agriculture. SAAG's work is articulated at three levels: with the policy-makers; with other NGOs/CBOs in Pakistan and in countries of the South; and at the grassroots level with the farmers. Among its activities, particularly successful is the promotion of exchange visit programmes among South Asian rural communities, focused on the enhancement of sustainable livelihoods and local innovations against hunger.

South Asian Network on Food, Ecology and Culture (SANFEC) is a network of over 30 NGOs from South Asia united in their goal to attain sustainable food production within an ecological, cultural and gender-sensitive framework. SANFEC's main concern is attainment of food security for small farmers and identification of the most appropriate production systems to ensure it. The network pro- motes a deep ecology paradigm for development and aims to enhance the value of farmers' knowledge system and practical experiences. It works for preservation of biodiversity, encourages proritization of food crops, and opposes an intellectual property rights regime on seeds and life patenting in general.

\section{Peru}

Fomento de la Vida (FOVIDA) works to promote food security and community development through a number of programmes focused on access to land, water, credit and technology; enhancement of entrepreneurial skills; access to health care and education; women's empowerment and promotion of civil society organizations. Among its programmes, FOVIDA monitors health, nutrition and sanitation at the community level (8620 households), provides technical assistance to small farmers, carries out lobbying and advocacy campaigns for food security and civil society participation. The organization represents the Latin American Region in the Global Forum for Sustainable Food and Nutritional Security.

\section{Senegal}

Société Africaine d'Education et de Formation pour le Développement (SAFEFOD) is a national NGO aiming to promote democracy and development at the national and regional level. Its activities focus on the enhancement of leadership skills in local communities; establishment of ongoing dialogue among civil society organizations and the state; promotion of decentralized structure of resource mobilization and investment at the local level. These strategies are instrumental to support SAFEFOD's efforts for food security and poverty alleviation in its social, cultural, political and economic dimension. 


\section{South Africa}

Agriculture Research Council (ARC) is committed to the promotion of agricultural research, technology development and technology transfer towards optimizing the role of agriculture in the national growth and development. Through its wide network of research institutes and experimental farms, ARC seeks to support national and household food security through the empowerment of both commercial and resourcepoor farmers. ARC-generated technologies also underpin micro, small and medium enterprises with a view to job creation. ARC research and activities focus on applied science and technology, health and nutrition, food safety, education, environment and natural resources conservation.

\section{Tanzania}

Mwasama School is not only an education centre but also a capacity building organization that provides training in participation and small entrepreneurship. Further activities are implemented in the field of sustainable livelihoods, food security, women and development.

\section{Tunisia}

El Taller works to facilitate a dynamic process of international and inter-regional exchange and dialogue among social movements and civil society organizations. It aims to challenge structural causes of dispossession, destruction of cultures and deepening of poverty. The organization seeks non-violent means to social transformation and searches for alternatives to the dominant discourses on human rights, development, security and women. Among its current initiatives are the building of international coalitions and networks reflecting on issues of new forms of governance, science and the sacred; the organization of regional courses on NGO leadership and development; the establishment of women's courts; six regional programmes seeking out the roots of submerged knowledges and wisdoms; and a programme for the enhancement of dialogue and solidarity in the Arab region.

\section{Uganda}

Institute of Public Health is a department of Makerere University, one of the oldest universities in Africa with a track record of academic excellence. The institute is particularly active in research on food and nutrition issues, with a particular focus on the impact of globalization on health.

Ssemwanga Centre for Agriculture and Food is a research-oriented organization concerned with rural community development issues. Beyond research activities in the field of agricultural technology and food processing, the centre provides training to small farmers and women's groups in order to enhance their food security.

\section{Yemen}

Scientific Council for Systems and Applied Sciences (SCSAS) is a private organization providing consultancy and training on development of rural communities, water management, agricultural production, food processing and environmental issues. The organization aims to strengthen efforts of local communities towards food security and encourage community participation in decision-making processes, provide a forum for exchange of ideas and discussion among international and governmental agencies, charities and local community who have made substantial efforts to counter poverty and hunger, and accelerate social development.

\section{Zambia}

Programme Against Malnutrition (PAM) aims to contribute to poverty eradication strategies by means of improved household food security, income and nutrition. It offers services towards enhancement of safety nets, particularly targeting households which are affected by food production failure and national calamities. It promotes sustainable agriculture and capacity building among NGOs, CBOs and civil society by-and-large; supports the improvement of entrepreneurial skills among the rural poor; and conducts advocacy initiatives aimed at enhanced food security and sustainable livelihoods.

\section{Zimbabwe}

Zimbabwe Women's Bureau (ZWB) is a local/national women's NGO whose membership currently stands at more than 6000 individual and institutional members concerned with participatory, pluralistic and sustainable development of women. The mission of ZWB is to improve the socio-economic status of women by provision of training, information and material support for sustainable development programmes. The organization focuses on the promotion of women's micro-enterprises; capacity building and institutional development of community-based organizations; promotion of local and regional networking; awareness raising in gender, health and civic issues; basic and functional literacy; improvement of household food security through self-help sustainable land use and environmentally friendly sustainable resource management; provision of affordable finance and appropriate technology. 